\title{
Gene Expression Differences between Ductal Carcinoma in Situ with and without Progression to Invasive Breast Cancer
}

Shusma C. Doebar, ${ }^{*}$ Anieta M. Sieuwerts, ${ }^{\dagger}$ Vanja de Weerd, ${ }^{\dagger}$ Hans Stoop, ${ }^{*}$ John W.M. Martens, ${ }^{\dagger}$ and Carolien H.M. van Deurzen ${ }^{*}$

From the Departments of Pathology* and Medical Oncology and Cancer Genomics Netherlands, ${ }^{\dagger}$ Erasmus MC Cancer Institute, Rotterdam, the Netherlands

Accepted for publication

March 27, 2017.

Address correspondence to Shusma C. Doebar, M.D., Erasmus MC Cancer Institute, PO Box 2040, 3000 CA Rotterdam, the Netherlands. E-mail: s.doebar@ erasmusmc.nl.

\begin{abstract}
To understand the molecular alterations driving the progression of ductal carcinoma in situ (DCIS), we compared patients with pure DCIS and patients with DCIS and synchronous invasive breast cancer (IBC). Twelve patients with extensive pure DCIS were included as a representation of indolent lesions with limited invasive capacity. These cases were matched with 12 patients with a limited DCIS component and IBC, representing lesions with a high invasive potential. Matching included age and surrogate DCIS subtypes. Gene expression profiling was performed on DCIS cells to identify transcriptional differences between these two groups. The identified genes were validated by immunohistochemistry. Nine genes showed significantly different expression. Most of these genes were highly expressed in DCIS samples with IBC, including PLAU $(P=0.002), \operatorname{COL1A1}(P=0.006)$, KRT81 $(P=0.009)$, S100A7 $(P=0.015)$, SCGB1D2 $(P=0.023)$, KRT18 $(P=0.029)$, and NOTCH3 $(P=0.044)$, whereas EGFR and CXCL14 showed a higher expression in cases with pure DCIS $(P=0.015$ and $P=0.028$, respectively). This difference was only significant for SCGB1D2 $(P=0.009)$. Hierarchical clustering revealed distinct clustering of patients with and without invasion. Patients with pure DCIS have a different gene expression pattern as compared to patients with DCIS and synchronous IBC. These genes may pinpoint to driver pathway(s) that play an important role in DCIS progression. (Am J Pathol 2017, 187: 1648-1655; http:// dx.doi.org/10.1016/j.ajpath.2017.03.012)
\end{abstract}

Ductal carcinoma in situ (DCIS) is a nonobligate precursor lesion of invasive breast cancer (IBC). ${ }^{1}$ In the past decades, the detection rate of DCIS increased dramatically as a result of the increased use and improved resolution of mammographic screening. ${ }^{2}$ Nowadays, DCIS accounts for $15 \%$ to $30 \%$ of all new breast cancer cases detected in a well-screened population. ${ }^{1,2}$

The mechanism behind progression of DCIS to IBC remains to be elucidated. In daily practice, most patients with pure DCIS are treated with local resection with or without radiation. Therefore, data are limited regarding the biological behavior of DCIS. Only a few small retrospective studies reported on the frequency of progression of untreated patients with a biopsy diagnosis of pure DCIS. ${ }^{3,4}$ In these series, approximately $40 \%$ to $50 \%$ of cases progressed to IBC after a follow-up of 20 to 30 years, whereas the other cases remained indolent.
There is much debate regarding the optimal treatment of DCIS. Because DCIS is a noninvasive disease, current local treatment protocols result in overtreatment for many patients, which is associated with increased costs and morbidity without clinical benefit. On the other hand, a substantial proportion of DCIS cases progress to IBC and, obviously, these patients may benefit from prevention and early treatment.

Paired comparative genomic assays have widely been performed on cases with DCIS and synchronous IBC, showing a high genomic resemblance. ${ }^{5-7}$ However, comparative genomic assays of pure DCIS versus DCIS with progression to IBC are sparse and partly biased by the inclusion of different DCIS subtypes. ${ }^{8-10}$ Recent studies

Supported by the Erasmus MC Cancer Institute (S.C.D.).

Disclosures: None declared. 
reported differences in the behavior of DCIS according to DCIS subtypes, based on immunohistochemistry or gene expression patterns. ${ }^{11-17}$ These reported features allow some recurrence risk prediction, but they are not widely used to select individual patients who can avoid adjuvant therapy. ${ }^{15}$ The identification of novel genetic alterations and molecular pathways underlying the transformation from DCIS to IBC may help to establish biomarkers that have the potential to distinguish low-risk patients who do not require aggressive treatment and high-risk patients who are likely to progress to IBC.

In daily practice, a proportion of patients presents with extensive involvement of the breast with DCIS without any signs of invasion. Although one cannot exclude that these cases would progress over time, the DCIS growth pattern suggests that these cases have a limited invasive potential. On the other hand, other patients have a limited amount of DCIS adjacent to an invasive component or multiple foci of invasion, suggesting a high invasive potential. These differences in biological behavior of DCIS imply different alterations at the molecular level. On the basis of these observations, we attempted to identify molecular differences at the transcriptional level with robust quantitative RT-PCR assays. For this purpose, we compared breast tissues of patients with extensive DCIS (representing a group with limited invasive potential) with breast tissues of patients who presented with a limited DCIS component and synchronous IBC (as a surrogate for a DCIS subtype with a high invasive potential). On the basis of these data, we aimed to increase our understanding regarding molecular alterations driving DCIS progression and, consequently, facilitate the identification of novel, potential therapeutic targets.

\section{Materials and Methods}

\section{Patients}

In this retrospective study, two groups of patients were selected from the histopathology files of the Erasmus MC Cancer Institute (Rotterdam, the Netherlands). The first group included patients with extensive pure DCIS, which was defined as DCIS with a diameter of $\geq 5 \mathrm{~cm}$, to represent a group of DCIS with a biologically indolent behavior with limited invasive capacity. The second group included patients with a limited amount of DCIS (defined as DCIS with a diameter of $\leq 1 \mathrm{~cm}$ ) with adjacent IBC. This latter group was selected as a representation of a biologically aggressive type of DCIS with high invasive capacity. Patients from the first group were matched with patients from the second group to correct for potential confounders. Matching included age (categorized from 30 to 40, 40 to 50, 50 to 60 , and 70 to 80 years) and surrogate DCIS subtypes, as described below. Patients with a history of breast cancer, ipsilateral breast irradiation, or a $B R C A$ mutation were excluded.
We used coded leftover patient material in accordance with the Code of Conduct of the Federation of Medical Scientific Societies in the Netherlands (http://www.federa. org/codes-conduct, last accessed January 10, 2017). According to institutional and national guidelines, no informed consent was needed for this study.

\section{Pathological Evaluation}

Formalin-fixed, paraffin-embedded (FFPE) hematoxylin and eosin-stained whole sections of excision specimens were collected and reviewed by two pathologists (C.H.D. and S.C.D.). Cases of pure DCIS were extensively sampled, according to the national Dutch guidelines, with a minimum of 10 tissue blocks of the lesion (The Dutch Guidelines Database, https://richtlijnendatabase.nl/en/richtlijn/breast_ cancer/pathology/criteria_for_dcis.html, last accessed January 10, 2017). Histopathological features of DCIS included grade according The Dutch Guidelines Database $^{18}$ and surrogate subtyping based on immunohistochemistry, as originally described for IBC. ${ }^{19}$ According to these criteria, DCIS was categorized as luminal A [estrogen receptor $(\mathrm{ER})^{+}$, progesterone receptor (PR) high, Her2 ${ }^{-}$, Ki67 low], luminal B Her2 ${ }^{-}\left(\mathrm{ER}^{+}, \mathrm{Her} 2^{-}, \mathrm{PR}^{-}\right.$, or low and/or $\mathrm{Ki}-67$ high), luminal $\mathrm{B} \mathrm{Her} 2^{+}\left(\mathrm{ER}^{+}, \mathrm{Her}^{+}\right.$, any PR, any $\mathrm{Ki}-67)$, or nonluminal Her2 positive $\left(\mathrm{ER}^{-}, \mathrm{PR}^{-}, \mathrm{Her} 2^{+}\right)$. A cutoff of 20\% Ki-67 (MIB-1; Dako, Glostrup, Denmark) positive cells was used to distinguish cases with a low versus high proliferative index. Low progesterone (PR 1E2; Ventana, Tucson, AZ) expression was defined as $\leq 20 \%{ }^{20}$

Immunohistochemical evaluation was performed on FFPE whole slides ( $4 \mu \mathrm{m}$ thick) using the Ventana Benchmark Ultra automatic stainer. ER (ER SP1; Ventana) was considered positive when at least $10 \%$ of the DCIS cells were positive, irrespective of intensity (https://www.gov.uk/government/ collections/breast-screening-professional-guidance, last accessed January 10, 2017). Immunohistochemical HER2 expression (Her2 4B5; Ventana) was scored on all cases, according to international guidelines. ${ }^{21}$ Equivocal cases were evaluated by silver in situ hybridization.

We also stained for P53 (BP53-11; Ventana), which was considered aberrant in case of a confluent negative staining or a strong diffuse positive staining. An intermediate expression of any intensity was considered to be normal. ${ }^{22}$

RNA Extraction, cDNA Synthesis, Preamplification, and Gene Expression Evaluation (Quantitative RT-PCR)

Areas composed of at least 50\% DCIS cells were microdissected from 10 to 15 hematoxylin and eosin-stained sections $(6 \mu \mathrm{m}$ thick) of FFPE tissue. Microdissection was performed with a sterile needle under a stereomicroscope (Zeiss, Oberkochen, Germany). On the basis of this method, contamination of other cell types (myoepithelial cells, stroma, lymphocytes) cannot completely be avoided. However, the estimated tumor cell percentage in our series 
was high $(75 \%$ to $90 \%$ in the group of patients with pure DCIS and $70 \%$ to $85 \%$ in the group of patients with DCIS and synchronous IBC). RNA was extracted from these cells using the Qiagen (Hamburg, Germany) AllPrep DNA/RNA FFPE Kit, according to the manufacturer's instructions. Concentrations were measured with a Nanodrop 1000 system (Thermo Fisher Scientific, Waltham, MA). cDNA was generated from a total of 100 ng RNA for 30 minutes at $48^{\circ} \mathrm{C}$ with RevertAid $\mathrm{H}$ minus (Thermo Fisher Scientific). Gene-specific preamplification was performed for 96 genes ( 93 tumor-specific genes and 3 reference genes, including GUSB, HMBS, and HPRT1), using the TaqMan PreAmp Master mix (ThermoFisher Scientific) for $15 \mathrm{cy}-$ cles. This was followed by TaqMan probe-based real-time PCRs, according to the manufacturer's instructions, in an MX3000P Real-Time PCR System (Agilent, Santa Clara, $\mathrm{CA})$.

These 93 tumor-specific target genes were selected based on their reported involvement in tumorigenesis and/or mutagenesis. ${ }^{23}$ Gene expression levels were quantified relative to the average expression of GUSB, HMBS, and HPRT1 using the 2 (average Cq reference genes - Cq target gene) method. Samples with an average reference gene expression of $\mathrm{Cq}>25$ were considered to be of insufficient RNA quality and were excluded from further analysis. In one of our previous studies, we compared the expression levels of 55 of our 93-gene panel between paired freshly frozen and FFPE samples and reported high levels of concordance (data not shown). ${ }^{24}$

\section{Immunohistochemistry and Gene Function}

Genes with a significantly different expression level between pure DCIS and DCIS with synchronous IBC were validated by immunohistochemistry. Antibodies and scoring methods are described below.

We used the DAVID Gene Functional Classification tool to evaluate the gene function of the differently expressed genes, according to Gene Ontology. ${ }^{25,26}$

\section{Statistical Analysis}

We used a paired-samples $t$-test (IBM SPSS statistics 23) to compare the expression levels of the 93 genes in matched pure DCIS and DCIS with synchronous IBC.

To evaluate whether pure DCIS cases could be distinguished from cases with DCIS and synchronous IBC, a DCIS index score was calculated to evaluate the impact of significant differences between the matched samples. For this DCIS index score, the paired-samples $t$-test was used in the following equation:

$\mathrm{SUM}_{1-9}$ ( $t$-test value gene $\mathrm{X}_{1} \times \Delta \mathrm{Cq}$ of gene transcript $\mathrm{X}_{1}+t$-test value gene $\mathrm{X}_{2} \times \Delta \mathrm{Cq}$ of gene transcript $\mathrm{X}_{2}+\ldots$. $t$-test value gene $\mathrm{X}_{9} \times \Delta \mathrm{Cq}$ of gene transcript $\mathrm{X}_{9}$ ) (1)

The $\chi^{2}$ test was used to analyze immunohistochemical differences between pure DCIS lesions and DCIS with synchronous IBC. $P<0.05$ was considered to be statistically significant.

\section{Results}

\section{Patients}

In total, 24 patients were included, divided into two matched groups of 12 patients each. The overall median age was 56 years (range, 31 to 80 years). The median age in the group of patients with pure DCIS was 55 years (range, 31 to 76 years); in the group with an adjacent invasive component, it was 58 years (range, 32 to 80 years). The median follow-up of patients with pure DCIS was 37 months (range, 24 to 76 months). No invasive recurrences or distant metastases were reported. In the pure DCIS group, the median DCIS size was $7 \mathrm{~cm}$ (range, 5 to $13 \mathrm{~cm}$ ). The DCIS lesions of both groups were graded as grade 2 or grade 3 . On the basis of immunohistochemical subtyping, nine matched pairs were categorized as luminal A subtype and three matched pairs as luminal B subtype. None of the cases showed an aberrant P53-staining pattern. Table 1 provides an overview of the clinicopathological features of the 12 matched pairs.

\section{Gene Expression Profiles of Matched Cases with Pure DCIS and DCIS with Synchronous IBC}

On the basis of the 93 selected genes, 9 showed a significant different expression between patients with pure DCIS and patients with DCIS and synchronous IBC. In total, 4 of 93 genes (AURKA, CD133, MAGEA3, and SNAPC2) were not expressed at all. Supplemental Table S1 provides an overview of the remaining 89 genes. The differently expressed genes included COL1A1, CXCL14, EGFR, KRT81, KRT18, NOTCH3, PLAU, S1OOA7, and SCGB1D2 (Table 2). Most of these nine genes were significantly highly expressed in DCIS samples with synchronous IBC as compared to pure DCIS cases: PLAU $(P=0.002)$, COL1A1 $(P=0.006)$, KRT81 $(P=0.009)$, S100A7 $(P=0.015)$, SCGB1D2 $(P=0.023), \operatorname{KRT18}(P=0.029)$, and NOTCH3 $(P=0.044)$. The remaining two genes, EGFR and CXCL14, showed a significantly higher expression in cases with pure DCIS as compared to cases with DCIS and synchronous $\operatorname{IBC}(P=0.015$ and $P=0.028$, respectively).

On the basis of these nine genes with a significantly different expression between both groups, a DCIS index score was calculated (Figure 1). The DCIS index value ranged from -2.31 to -86.84 . The optimal cutoff value to discriminate pure DCIS samples from DCIS samples with synchronous IBC was -65.16 (Figure 1A). Supervised hierarchical clustering analysis based on these nine genes separated the most pure DCIS lesions from DCIS lesions with synchronous IBC (Figure 1B). However, three samples of pure DCIS clustered within the group of DCIS cases with synchronous IBC as a result of a high DCIS index score. 
Table 1 Clinicopathological Features of Patients with Pure DCIS and Matched Patients with DCIS and Synchronous IBC

\begin{tabular}{|c|c|c|c|c|c|c|c|c|}
\hline Matched pairs & $\begin{array}{l}\text { Pure DCIS or DCIS and } \\
\text { synchronous IBC }\end{array}$ & Age, years & $\begin{array}{l}\text { Histological } \\
\text { grade DCIS }\end{array}$ & ER & PR & HER2 & Ki-67 & DCIS subtype \\
\hline \multirow[t]{2}{*}{1} & Pure DCIS & 56 & 3 & + & - & - & Low & Luminal B \\
\hline & $\mathrm{DCIS}+\mathrm{IBC}$ & 51 & 2 & + & + & - & High & Luminal B \\
\hline \multirow[t]{2}{*}{2} & Pure DCIS & 56 & 2 & + & + & - & Low & Luminal A \\
\hline & DCIS + IBC & 58 & 2 & + & + & - & Low & Luminal A \\
\hline \multirow[t]{2}{*}{3} & Pure DCIS & 61 & 2 & + & + & - & Low & Luminal A \\
\hline & DCIS + IBC & 67 & 2 & + & + & - & Low & Luminal A \\
\hline \multirow[t]{2}{*}{4} & Pure DCIS & 76 & 2 & + & + & - & Low & Luminal A \\
\hline & DCIS + IBC & 77 & 2 & + & + & - & Low & Luminal A \\
\hline \multirow[t]{2}{*}{5} & Pure DCIS & 51 & 2 & + & + & - & Low & Luminal A \\
\hline & DCIS + IBC & 59 & 2 & + & + & - & Low & Luminal A \\
\hline \multirow[t]{2}{*}{6} & Pure DCIS & 71 & 2 & + & + & - & Low & Luminal A \\
\hline & DCIS + IBC & 80 & 2 & + & + & - & Low & Luminal A \\
\hline \multirow[t]{2}{*}{7} & Pure DCIS & 53 & 2 & + & + & - & Low & Luminal A \\
\hline & $\mathrm{DCIS}+\mathrm{IBC}$ & 51 & 2 & + & + & - & Low & Luminal A \\
\hline \multirow[t]{2}{*}{8} & Pure DCIS & 54 & 2 & + & + & - & Low & Luminal A \\
\hline & $\mathrm{DCIS}+\mathrm{IBC}$ & 58 & 2 & + & + & - & Low & Luminal A \\
\hline \multirow[t]{2}{*}{9} & Pure DCIS & 53 & 3 & + & - & + & Low & Luminal B \\
\hline & DCIS + IBC & 51 & 2 & + & + & + & Low & Luminal B \\
\hline \multirow[t]{2}{*}{10} & Pure DCIS & 57 & 3 & + & - & - & Low & Luminal B \\
\hline & DCIS + IBC & 59 & 2 & + & - & - & Low & Luminal B \\
\hline \multirow[t]{2}{*}{11} & Pure DCIS & 31 & 2 & + & + & - & Low & Luminal A \\
\hline & DCIS + IBC & 32 & 3 & + & + & - & Low & Luminal A \\
\hline \multirow[t]{2}{*}{12} & Pure DCIS & 49 & 2 & + & + & - & Low & Luminal A \\
\hline & DCIS + IBC & 42 & 2 & + & + & - & Low & Luminal A \\
\hline
\end{tabular}

$n=12$ pairs.

+ , positive; -, negative; ER, estrogen receptor; IBC, invasive breast cancer; PR, progesterone receptor.

Notably, two of these three samples were PR negative and/or HER2 positive and, therefore, categorized as luminal B.

\section{Immunohistochemistry}

The identified nine genes with a significantly different gene expression between pure DCIS and DCIS with synchronous IBC were evaluated by immunohistochemistry. Figure 2 provides an overview of the immunohistochemical staining pattern. For each antibody, a representative case is shown.
As described above, seven of these nine genes showed a higher gene expression in cases with DCIS and synchronous IBC. Immunohistochemically, CK81 (catalog number H00003887-M01; Abnova, Taipei, Taiwan) and NOTCH3 (catalog number ab 23426; Abcam, Cambridge, UK) were only expressed in the myoepithelial cells, whereas the luminal cells were negative in both groups (Figure 2, A and B). COL1A1 (catalog number NB600-408; Novus Biologicals, Littleton, $\mathrm{CO}$ ) showed periductal stromal staining (Figure 2C) in six cases, but no significant difference $(P=0.317)$ was observed between both groups.

Table 2 Overview of Genes with a Significantly Different Expression between Pure DCIS and DCIS with Synchronous IBC

\begin{tabular}{|c|c|c|c|c|c|c|c|c|}
\hline \multirow[b]{2}{*}{ Gene } & \multirow[b]{2}{*}{ Gene name } & \multicolumn{6}{|c|}{ Paired differences } & \multirow{2}{*}{$\begin{array}{l}P \text { value } \\
\text { (two-tailed) }\end{array}$} \\
\hline & & Mean & SD & SEM & Lower* & Upper* & $\mathrm{T}$ & \\
\hline PLAU & Plasminogen activator, urokinase & 1.178 & 1.020 & 0.294 & 0.529 & 1.827 & 3.998 & 0.002 \\
\hline KRT81 & Keratin 81 & 2.346 & 2.563 & 0.740 & 0.717 & 3.975 & 3.171 & 0.009 \\
\hline EGFR & $\begin{array}{l}\text { Epidermal growth factor receptor [erythroblastic } \\
\text { leukemia viral (v-erb-b) oncogene homolog, avian] }\end{array}$ & -1.075 & 1.289 & 0.372 & -1.894 & -0.256 & -2.891 & 0.015 \\
\hline CXCL14 & Chemokine (C-X-C motif) ligand 14 & -1.481 & 2.025 & 0.584 & -2.768 & -0.194 & -2.534 & 0.028 \\
\hline KRT18 & $\begin{array}{l}\text { Keratin } 18 \text {; keratin } 18 \text { pseudogene } 26 \text {; keratin } \\
18 \text { pseudogene } 19\end{array}$ & 0.499 & 0.688 & 0.198 & 0.061 & 0.936 & 2.511 & 0.029 \\
\hline NOTCH3 & Notch homolog 3 (Drosophila) & 0.867 & 1.317 & 0.380 & 0.030 & 1.704 & 2.280 & 0.044 \\
\hline
\end{tabular}

IBC, invasive breast cancer.

*Upper and Lower refer to $95 \%$ confidence interval of the difference. 
A

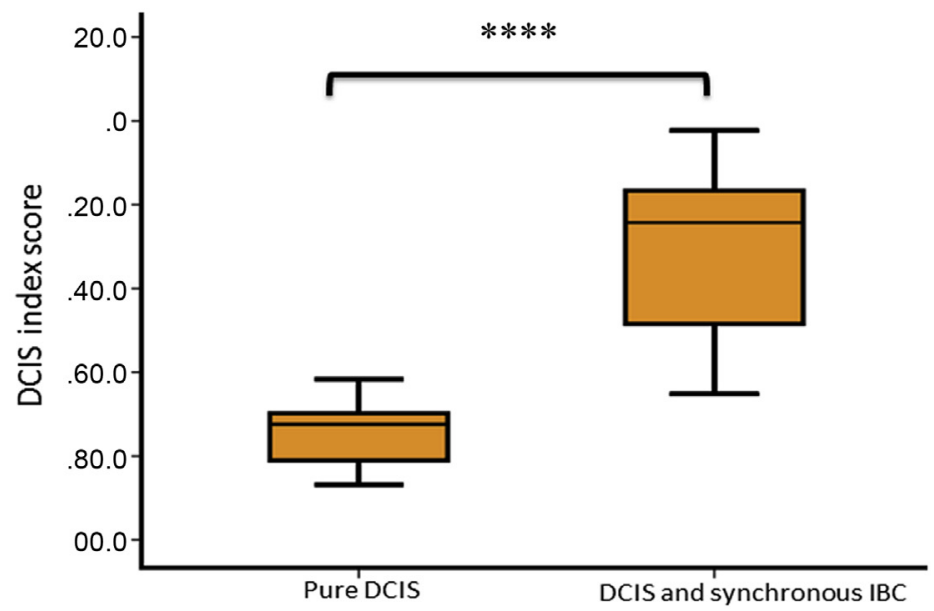

Figure 1 DCIS index scores of differently expressed genes between matched pairs of patients. A: Box plot with DCIS index scores that significantly differentiate patients with pure DCIS from patients with DCIS and synchronous IBC. B: Supervised clustering analysis demonstrated distinct clustering of patients with pure DCIS and patients with DCIS and synchronous IBC. Samples are ranked from low to high, according to their individual DCIS index score. In addition, the $\mathrm{Cq}$ values of each gene (horizontal) are shown for each individual sample (vertical). Data are expressed as box-and-whisker plots (A). ${ }^{*} 0$, without IBC; 1 , with IBC. ${ }^{* \star *} P<0.0001$.

B

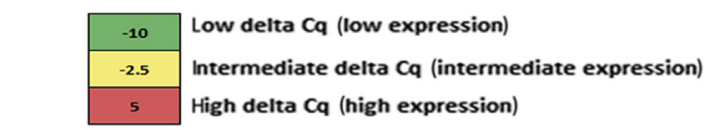

\begin{tabular}{|c|c|c|c|c|c|c|c|c|c|c|c|c|c|c|c|c|c|c|c|c|c|c|c|c|}
\hline $\begin{array}{l}\text { DCIS with or } \\
\text { without IBC* }\end{array}$ & 0 & 0 & 0 & 0 & 0 & 0 & 0 & 0 & 0 & 1 & 0 & 1 & 1 & 1 & 0 & 0 & 1 & 1 & 1 & 1 & 1 & 1 & 1 & 1 \\
\hline PLAU & $\mid-8.59$ & -8.05 & $\mid-7.09$ & -9.47 & $\mid-8.20$ & $|-9.29|$ & $|-6.00|$ & $\mid-8.77$ & -7.61 & -8.45 & -7.38 & $\mid-7.21$ & -8.16 & $|-5.74|$ & -7.28 & $\mid-6.47$ & -6.29 & $|-5.05|$ & $\mid-6.81$ & $|-5.59|$ & $|-6.33|$ & $|-7.89|$ & $\mid-6.99$ & -7.34 \\
\hline $\operatorname{COL1A1}$ & $|-0.60|$ & -0.12 & $\mid-0.49$ & 0.73 & $\mid-0.10$ & 0.71 & -0.82 & $\mid-3.37$ & -0.78 & 0.37 & 1.39 & 1.56 & 0.39 & $|4.22|$ & 3.73 & -0.04 & -0.34 & -2.35 & 2.03 & 1.16 & 0.83 & 4.36 & 2.84 & 4.16 \\
\hline KRTR1 & $\mid-10.00$ & -9.64 & $\mid-10.00$ & -10.00 & \begin{tabular}{|l|}
$\mid-9.49$ \\
\end{tabular} & -10.00 & $\mid-9.46$ & -7.13 & -10.00 & -10.00 & -10.00 & $\mid-9.69$ & -5.28 & $\mid-3.59$ & -9.36 & -8.21 & -7.81 & -9.25 & $\mid-5.79$ & -9.07 & -6.66 & -5.25 & -6.97 & -9.44 \\
\hline S1OOA7 & $\mid-8.49$ & -8.42 & -10.00 & -9.30 & $|-9.97|$ & -5.25 & $\mid-10.00$ & -3.38 & -3.07 & $\mid-6.64$ & $\mid-7.33$ & $\mid-2.28$ & -6.57 & $\mid-9.36$ & -4.37 & -6.52 & -8.59 & -5.07 & -4.11 & -3.33 & $\mid-1.31$ & $\mid-2.70$ & -3.45 & 0.44 \\
\hline SCGB1D2 & -5.93 & -7.76 & $\mid-5.32$ & -3.80 & -5.04 & $\mid-8.49$ & -4.75 & $\mid-9.18$ & -6.43 & $\mid-2.22$ & $\mid-1.64$ & $\mid-8.97$ & -5.13 & $\mid-8.77$ & -2.16 & $\mid 1.03$ & 0.85 & 1.59 & -3.75 & 0.14 & $\mid-0.12$ & \begin{tabular}{|l|} 
\\
\end{tabular} & -0.02 & 0.89 \\
\hline KRT18 & 1.55 & 2.66 & 1.71 & 1.69 & 1.17 & 1.96 & 2.89 & 3.28 & 1.62 & 1.67 & 1.26 & 2.52 & 2.37 & 1.63 & 1.73 & 3.43 & 3.75 & 2.54 & 1.95 & 2.99 & 2.91 & 1.92 & 2.39 & 3.47 \\
\hline NOTCH3 & -0.54 & -0.54 & -0.66 & -1.16 & \begin{tabular}{|l|}
-1.72 \\
\end{tabular} & -1.50 & -0.51 & -0.42 & -1.44 & -0.12 & 0.79 & \begin{tabular}{|l|}
-1.64 \\
\end{tabular} & -0.77 & -0.20 & $\mid-0.87$ & 0.45 & 1.25 & -0.48 & 0.92 & -1.22 & 0.01 & 1.79 & 0.39 & 1.28 \\
\hline CXCL14 & -1.38 & -1.20 & -2.03 & -1.62 & -2.34 & -1.71 & -1.83 & -4.06 & -1.64 & \begin{tabular}{|l|}
-1.70 \\
\end{tabular} & -0.97 & -2.69 & -2.46 & \begin{tabular}{|l|}
-1.04 \\
\end{tabular} & $|-0.07|$ & -1.34 & -4.38 & -7.04 & -5.50 & -2.95 & -2.41 & \begin{tabular}{|l|}
-1.22 \\
\end{tabular} & -3.63 & -2.59 \\
\hline EGFR & \begin{tabular}{|l|} 
\\
\end{tabular} & -4.55 & $|-4.26|$ & -5.92 & $\mid-6.88$ & \begin{tabular}{|l|} 
\\
\end{tabular} & \begin{tabular}{|l|} 
\\
\end{tabular} & $|-4.62|$ & -5.24 & \begin{tabular}{|l|}
-5.46 \\
\end{tabular} & $|-4.41|$ & $\mid-6.47$ & -6.26 & \begin{tabular}{|l|} 
\\
\end{tabular} & \begin{tabular}{|l|}
-6.23 \\
\end{tabular} & $|-4.71|$ & $|-7.94|$ & -6.85 & -5.23 & $\mid-7.15$ & $|-4.77|$ & \begin{tabular}{|l|}
-5.82 \\
\end{tabular} & -7.11 & -7.21 \\
\hline DCIS index & $|-86.84|$ & -86.25 & $|-84.30|$ & -81.02 & $|-80.37|$ & $\mid-75.00$ & $|-72.40|$ & -72.35 & -70.57 & -65.16 & -61.66 & -56.37 & -51.95 & $\mid-48.44$ & $\mid-43.68$ & -41.39 & -27.19 & -25.06 & -24.29 & -23.4 & $\mid-20.43$ & $\mid-16.63$ & $|-13.60|$ & -2.31 \\
\hline
\end{tabular}

SCGB1D2 (lipophilin B; catalog number NBP1-81304; Novus Biologicals) was positive in the cytoplasm of neoplastic DCIS cells (Figure 2D) and was scored dichotomous (negative/weak or moderate/strong). There was a significantly higher expression in cases with DCIS and synchronous IBC as compared to the pure DCIS cases $(P=0.009)$, which was in line with the gene expression pattern of SCGB1D2.

S100A7 (catalog number NB100-56559; Novus Biologicals) was positive in the nucleus of the neoplastic DCIS cells (Figure 2E) and was also scored dichotomous (negative/ weak or moderate/strong). Although no significantly different expression was seen between both groups, there was a trend toward a higher expression in those cases with DCIS and synchronous IBC as compared to the pure DCIS cases $(P=0.150)$. CK18 (catalog number HPA001605; SigmaAldrich, Darmstadt, Germany) and urokinase plasminogen activator (clone 150; Grünenthal, Stolberg, Germany) were expressed cytoplasmatically in the neoplastic DCIS cells (Figure 2, F and G). No difference was seen between both groups $(P=0.48$ and $P=0.572$, respectively).

Epidermal growth factor receptor $(E G F R)$ and $C X C L 14$ showed a higher gene expression in the group of patients with pure DCIS. Immunohistochemically, EGFR (3C6 7902988; Ventana) was only expressed in myoepithelial cells (Figure $2 \mathrm{H}$ ). None of the cases showed expression in the luminal cells. Immunohistochemical evaluation of CXCL14 was not feasible because of a non-specific staining pattern.

\section{Functional Annotation of Differently Expressed Genes according to Gene Ontology}

According to Gene Ontology, a total of five genes (of the nine differently expressed genes) were annotated. These 


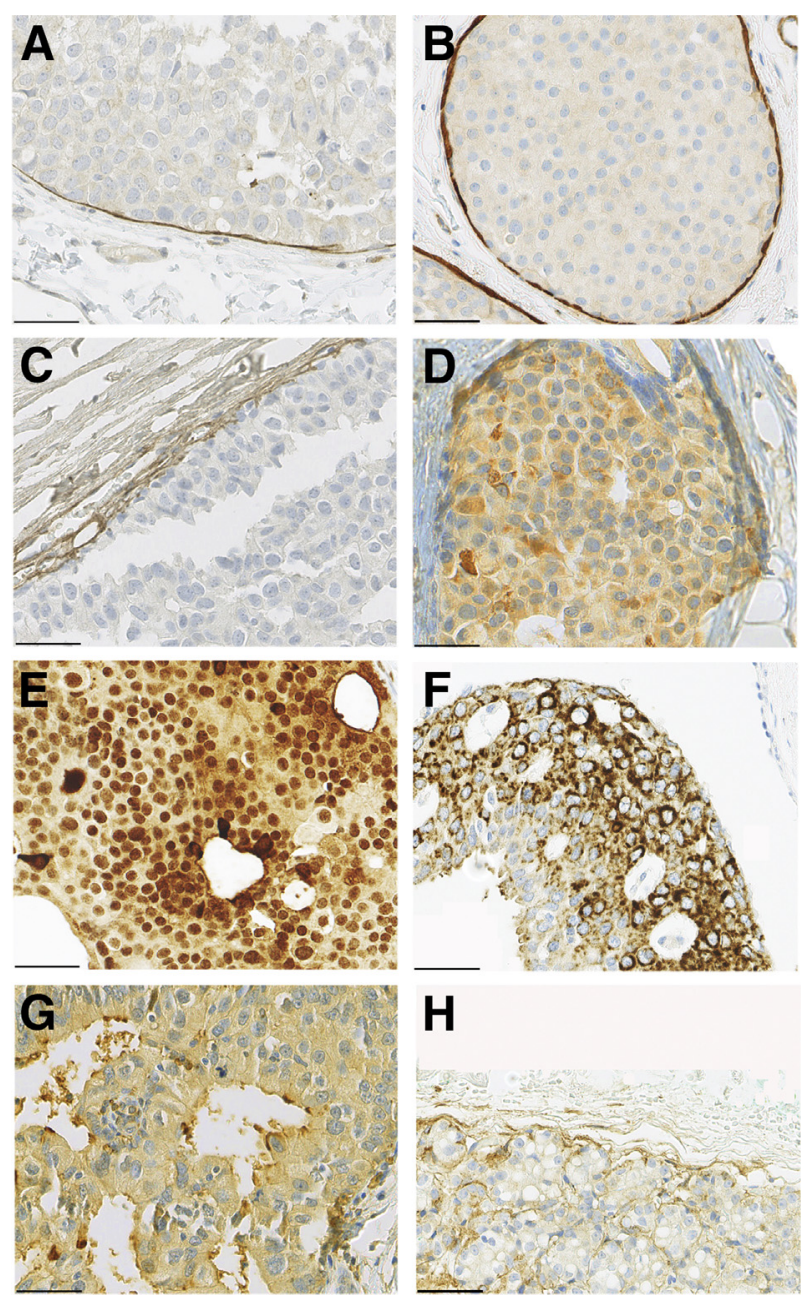

Figure 2 Staining pattern for each antibody. A and B: CK81 (A) and NOTCH3 (B) are positive in the myoepithelial cells and negative in the neoplastic DCIS cells. C: COL1A1 shows periductal stromal staining. D-G: SCGB1D2 (D) is positive in the cytoplasm of neoplastic DCIS cells, and S100A7 (E) shows nuclear staining. Both CK18 (F) and urokinase plasminogen activator $(\mathbf{G})$ are positive in the cytoplasm of neoplastic DCIS cells. H: Epidermal growth factor receptor is positive in the myoepithelial cells and negative in the neoplastic DCIS cells. Scale bars $=50 \mathrm{~mm}(\mathbf{A}-\mathbf{H})$.

genes are involved in several biological processes, including signal transduction (EGFR, CXCL14, and PLAU), chemotaxis (CXCL14 and PLAU), angiogenesis (S100A7 and $P L A U)$, cellular response to epidermal growth factor stimulus (EGFR and COL1A1), positive regulation of extracellular signal regulated kinase 1 and 2 cascade $(E F G R$ and S100A7), response to hyperoxia (COL1A1 and PLAU), and cellular response to amino acid stimulus (EGFR and COL1A1). None of these functions were statistically significantly enriched $(P>0.05)$ compared to the functions annotated to the total list of 93 measured genes.

\section{Discussion}

To achieve optimal individualized treatment for patients with DCIS, it is necessary to unravel the molecular events that contribute to DCIS progression. In this study, we identified significantly different gene expression profiles between patients with extensive pure DCIS (representing a group with a biologically indolent behavior) and patients with a limited amount of DCIS and synchronous IBC (representing a group with a biologically aggressive behavior). Most of these differently expressed genes (7/9) showed a higher expression in the DCIS group with synchronous IBC, including PLAU, COL1A1, KRT81, S1OOA7, SCGB1D2, KRT18, and NOTCH3. At the protein level, this could only be confirmed for SCGB1D2. The remaining two genes, EGFR and CXCL14, were upregulated in pure DCIS lesions at the transcriptional level. These findings are in line with previous studies that reported differences between pure DCIS lesions and DCIS with synchronous IBC based on gene copy number changes and whole exome sequencing. ${ }^{10,27}$

On the basis of these identified genes, supervised hierarchical cluster analysis showed distinct clustering for patients with pure DCIS (characterized by lower expression levels) and patients with DCIS and synchronous IBC (characterized by higher expression levels). However, three patients with pure DCIS clustered within the group of DCIS cases with synchronous IBC. Two of these three cases were classified as luminal $\mathrm{B}$, which might explain a gene expression profile that is more similar to DCIS with synchronous IBC. ${ }^{15,28}$

The progression of in situ to invasive carcinoma is a multistep process that includes several biological processes (ie, regulation of transcription, cell adhesion, immune response, chemotaxis, apoptosis, and cell proliferation). ${ }^{8,29,30}$ According to Gene Ontology, the differently expressed genes in our study are involved in several of these processes, mainly signal transduction. This suggests that signal transduction might play an important role in the progression of DCIS. In our series, COLIAI and NOTCH3 were up-regulated in cases with DCIS with synchronous IBC as compared to pure DCIS cases. This is in line with previous studies that reported that these genes have an important role in cell adhesion and migration. ${ }^{31,32}$ Furthermore, NOTCH3 plays an important role in cell growth by the inhibition of apoptosis and induction of cell proliferation, although the exact mechanism in breast cancer remains unknown. ${ }^{32}$ Another gene with an important role in cell growth is $\mathrm{CXCL14}$, although in contrast to $\mathrm{NOTCH3}$, overexpression of this gene inhibits cell proliferation and invasion. ${ }^{33}$ In line with this, a recent study reported that this gene is a negative regulator of growth and metastases in breast cancer. This anticancer effect correlates with the upregulation of CXCL14 in pure DCIS samples in our study, where it might have contributed to the indolent behavior. ${ }^{33}$

Several previous studies reported that disruption of the myoepithelial cell layer is one of the critical events in DCIS progression. ${ }^{8,34}$ This is in line with the results of our study, in which several of the up-regulated genes (EGFR, COL1A1, KRT81, and NOTCH3) are involved in the 
myoepithelial cell layer. ${ }^{29,34,35}$ Our finding that up-regulation of these genes was reported in both groups suggests that they could have both proinvasive and antiinvasive effects. Besides, it makes it unlikely that this finding was influenced by the amount of myoepithelial cells in the analyses. EGFR has been described as a specific marker in myoepithelial cells of the breast. ${ }^{35}$ COL1A1, together with other members of the collagenase family, was recently characterized as a myoepithelial-type gene in ER-positive breast cancer. $^{29}$ Regarding KRT81 and NOTCH3, we could not find such data in the literature, although we identified this protein in the myoepithelial compartment by immunohistochemistry.

The strength of our study is that we matched for surrogate DCIS subtypes. This was assumed to be more reliable than matching on grade, which is known to be a subjective feature. Ideally, matching should also be based on other factors (including grade, PR status, and Ki-67 index) because these factors could affect biological behavior, but this was not feasible. Our study also has several other limitations, in particular the sample size, and as such, our work should be considered as a hypothesis-generating study. In addition, the presence of an invasive component cannot be ruled out in those cases classified as pure DCIS. However, because these specimens were examined extensively, it is unlikely that a large invasive component was missed.

The immunohistochemical staining provided important information regarding the localization of the expression (neoplastic cells, myoepithelial cells, or periductal stroma), but the ability to detect different expression levels between pure DCIS and DCIS with synchronous IBC was limited by group size. Besides, we only evaluated a subset of luminallike cases. Although this is the most common subtype, our data cannot be extrapolated to other DCIS subtypes (eg, ERnegative/HER2-positive cases and triple-negative cases). Furthermore, because we evaluated only a selected number of tumor-specific target genes, it is likely that some cancer genes and functional pathways have been missed.

In conclusion, we reported distinct gene expression profiles in cases with pure DCIS and cases with DCIS and synchronous IBC. If these results can be validated in independent and larger cohorts, these differently expressed genes could be used to predict progression in individual patients diagnosed with DCIS to facilitate individualized treatment. Besides, these genes may pinpoint potentially targetable driver pathway(s) that play an important role in the progression of DCIS to IBC, which could ultimately result in the prevention of progression.

\section{Acknowledgments}

We thank Michelle van der Vlugt-Daane for technical assistance, Marcel Smid for statistical support, and Frank van Rooij for advice regarding study design.

\section{Supplemental Data}

Supplemental material for this article can be found at http://dx.doi.org/10.1016/j.ajpath.2017.03.012.

\section{References}

1. Burstein HJ, Polyak K, Wong JS, Lester SC, Kaelin CM: Ductal carcinoma in situ of the breast. N Engl J Med 2004, 350:1430-1441

2. Ernster VL, Barclay J, Kerlikowske K, Grady D, Henderson C: Incidence of and treatment for ductal carcinoma in situ of the breast. JAMA 1996, 275:913-918

3. Collins LC, Tamimi RM, Baer HJ, Connolly JL, Colditz GA, Schnitt SJ: Outcome of patients with ductal carcinoma in situ untreated after diagnostic biopsy: results from the Nurses' Health Study. Cancer 2005, 103:1778-1784

4. Sanders ME, Schuyler PA, Dupont WD, Page DL: The natural history of low-grade ductal carcinoma in situ of the breast in women treated by biopsy only revealed over 30 years of long-term follow-up. Cancer 2005, 103:2481-2484

5. Aubele M, Mattis A, Zitzelsberger H, Walch A, Kremer M, Welzl G, Hofler H, Werner M: Extensive ductal carcinoma in situ with small foci of invasive ductal carcinoma: evidence of genetic resemblance by CGH. Int J Cancer 2000, 85:82-86

6. Johnson CE, Gorringe KL, Thompson ER, Opeskin K, Boyle SE Wang Y, Hill P, Mann GB, Campbell IG: Identification of copy number alterations associated with the progression of DCIS to invasive ductal carcinoma. Breast Cancer Res Treat 2012, 133:889-898

7. Ma XJ, Salunga R, Tuggle JT, Gaudet J, Enright E, McQuary P, Payette T, Pistone M, Stecker K, Zhang BM, Zhou YX, Varnholt H, Smith B, Gadd M, Chatfield E, Kessler J, Baer TM, Erlander MG, Sgroi DC: Gene expression profiles of human breast cancer progression. Proc Natl Acad Sci U S A 2003, 100:5974-5979

8. Knudsen ES, Ertel A, Davicioni E, Kline J, Schwartz GF, Witkiewicz AK: Progression of ductal carcinoma in situ to invasive breast cancer is associated with gene expression programs of EMT and myoepithelia. Breast Cancer Res Treat 2012, 133:1009-1024

9. Miron A, Varadi M, Carrasco D, Li H, Luongo L, Kim HJ, Park SY, Cho EY, Lewis G, Kehoe S, Iglehart JD, Dillon D, Allred DC, Macconaill L, Gelman R, Polyak K: PIK3CA mutations in in situ and invasive breast carcinomas. Cancer Res 2010, 70:5674-5678

10. Kim SY, Jung SH, Kim MS, Baek IP, Lee SH, Kim TM, Chung YJ, Lee SH: Genomic differences between pure ductal carcinoma in situ and synchronous ductal carcinoma in situ with invasive breast cancer. Oncotarget 2015, 6:7597-7607

11. Meijnen P, Peterse JL, Antonini N, Rutgers EJ, van de Vijver MJ Immunohistochemical categorisation of ductal carcinoma in situ of the breast. Br J Cancer 2008, 98:137-142

12. Clark SE, Warwick J, Carpenter R, Bowen RL, Duffy SW, Jones JL: Molecular subtyping of DCIS: heterogeneity of breast cancer reflected in pre-invasive disease. Br J Cancer 2011, 104:120-127

13. Knopfelmacher A, Fox J, Lo Y, Shapiro N, Fineberg S: Correlation of histopathologic features of ductal carcinoma in situ of the breast with the oncotype DX DCIS score. Mod Pathol 2015, 28:1167-1173

14. Solin LJ, Gray R, Baehner FL, Butler SM, Hughes LL, Yoshizawa C, Cherbavaz DB, Shak S, Page DL, Sledge GW Jr, Davidson NE, Ingle JN, Perez EA, Wood WC, Sparano JA, Badve S: A multigene expression assay to predict local recurrence risk for ductal carcinoma in situ of the breast. J Natl Cancer Inst 2013, 105:701-710

15. Williams KE, Barnes NL, Cramer A, Johnson R, Cheema K, Morris J, Howe M, Bundred NJ: Molecular phenotypes of DCIS predict overall and invasive recurrence. Ann Oncol 2015, 26:1019-1025

16. Zhou W, Jirstrom K, Amini RM, Fjallskog ML, Sollie T, Lindman H, Sorlie T, Blomqvist C, Warnberg F: Molecular subtypes in ductal 
carcinoma in situ of the breast and their relation to prognosis: a population-based cohort study. BMC Cancer 2013, 13:512

17. Doebar SC, van den Broek EC, Koppert LB, Jager A, Baaijens MH, Obdeijn IM, van Deurzen CH: Extent of ductal carcinoma in situ according to breast cancer subtypes: a population-based cohort study. Breast Cancer Res Treat 2016, 158:179-187

18. Consensus Conference Committee: Consensus conference on the classification of ductal carcinoma in situ. Cancer 1997, 80:1798-1802

19. Goldhirsch A, Winer EP, Coates AS, Gelber RD, Piccart-Gebhart M, et al: Personalizing the treatment of women with early breast cancer: highlights of the St Gallen International Expert Consensus on the Primary Therapy of Early Breast Cancer 2013. Ann Oncol 2013, 24: 2206-2223

20. Prat A, Cheang MC, Martin M, Parker JS, Carrasco E, Caballero R, Tyldesley S, Gelmon K, Bernard PS, Nielsen TO, Perou CM: Prognostic significance of progesterone receptor-positive tumor cells within immunohistochemically defined luminal A breast cancer. J Clin Oncol 2013, 31:203-209

21. Wolff AC, Hammond ME, Hicks DG, Dowsett M, McShane LM, Allison KH, Allred DC, Bartlett JM, Bilous M, Fitzgibbons P, Hanna W, Jenkins RB, Mangu PB, Paik S, Perez EA, Press MF, Spears PA, Vance GH, Viale G, Hayes DF; American Society of Clinical Oncology, College of American Pathologists: Recommendations for human epidermal growth factor receptor 2 testing in breast cancer: American Society of Clinical Oncology/College of American Pathologists clinical practice guideline update. J Clin Oncol 2013, 31: 3997-4013

22. Boyle DP, McArt DG, Irwin G, Wilhelm-Benartzi CS, Lioe TF, Sebastian E, McQuaid S, Hamilton PW, James JA, Mullan PB, Catherwood MA, Harkin DP, Salto-Tellez M: The prognostic significance of the aberrant extremes of p53 immunophenotypes in breast cancer. Histopathology 2014, 65:340-352

23. Sieuwerts AM, Mostert B, Bolt-de Vries J, Peeters D, de Jongh FE, Stouthard JM, Dirix LY, van Dam PA, Van Galen A, de Weerd V, Kraan J, van der Spoel P, Ramirez-Moreno R, van Deurzen $\mathrm{CH}$, Smid M, Yu JX, Jiang J, Wang Y, Gratama JW, Sleijfer S, Foekens JA, Martens JW: mRNA and microRNA expression profiles in circulating tumor cells and primary tumors of metastatic breast cancer patients. Clin Cancer Res 2011, 17:3600-3618

24. Onstenk W, Sieuwerts AM, Weekhout M, Mostert B, Reijm EA, van Deurzen CH, Bolt-de Vries JB, Peeters DJ, Hamberg P, Seynaeve C, Jager A, de Jongh FE, Smid M, Dirix LY, Kehrer DF, van Galen A, Ramirez-Moreno R, Kraan J, Van M, Gratama JW, Martens JW, Foekens JA, Sleijfer S: Gene expression profiles of circulating tumor cells versus primary tumors in metastatic breast cancer. Cancer Lett 2015, 362:36-44

25. Huang da W, Sherman BT, Lempicki RA: Systematic and integrative analysis of large gene lists using DAVID bioinformatics resources. Nat Protoc 2009, 4:44-57

26. Huang da W, Sherman BT, Lempicki RA: Bioinformatics enrichment tools: paths toward the comprehensive functional analysis of large gene lists. Nucleic Acids Res 2009, 37:1-13

27. Iakovlev VV, Arneson NC, Wong V, Wang C, Leung S, Iakovleva G, Warren K, Pintilie M, Done SJ: Genomic differences between pure ductal carcinoma in situ of the breast and that associated with invasive disease: a calibrated aCGH study. Clin Cancer Res 2008, 14: 4446-4454

28. Lazzeroni M, Guerrieri-Gonzaga A, Botteri E, Leonardi MC, Rotmensz N, Serrano D, Varricchio C, Disalvatore D, Del Castillo A, Bassi F, Pagani G, DeCensi A, Viale G, Bonanni B, Pruneri G: Tailoring treatment for ductal intraepithelial neoplasia of the breast according to Ki-67 and molecular phenotype. Br J Cancer 2013, 108: $1593-1601$

29. Grigoriadis A, Mackay A, Reis-Filho JS, Steele D, Iseli C, Stevenson BJ, Jongeneel CV, Valgeirsson H, Fenwick K, Iravani M, Leao M, Simpson AJ, Strausberg RL, Jat PS, Ashworth A, Neville AM, O'Hare MJ: Establishment of the epithelial-specific transcriptome of normal and malignant human breast cells based on MPSS and array expression data. Breast Cancer Res 2006, 8:R56

30. Hanahan D, Weinberg RA: The hallmarks of cancer. Cell 2000, 100: $57-70$

31. Chai F, Liang Y, Zhang F, Wang M, Zhong L, Jiang J: Systematically identify key genes in inflammatory and non-inflammatory breast cancer. Gene 2016, 575:600-614

32. Leong KG, Karsan A: Recent insights into the role of Notch signaling in tumorigenesis. Blood 2006, 107:2223-2233

33. Gu XL, Ou ZL, Lin FJ, Yang XL, Luo JM, Shen ZZ, Shao ZM: Expression of CXCL14 and its anticancer role in breast cancer. Breast Cancer Res Treat 2012, 135:725-735

34. Vargas AC, McCart Reed AE, Waddell N, Lane A, Reid LE, Smart CE, Cocciardi S, da Silva L, Song S, Chenevix-Trench G, Simpson PT, Lakhani SR: Gene expression profiling of tumour epithelial and stromal compartments during breast cancer progression. Breast Cancer Res Treat 2012, 135:153-165

35. Santini D, Ceccarelli C, Tardio ML, Taffurelli M, Marrano D: Immunocytochemical expression of epidermal growth factor receptor in myoepithelial cells of the breast. Appl Immunohistochem Mol Morphol 2002, 10:29-33 